\title{
Statistics, Classification, and the Standardisation of Melancholia
}

No class of diseases with which man is afflicted are as various in their manifestations, as those known under the general term of insanity. No diseases present such an infinite variety of light and shade belonging to their own nature, or to their own intermixture with other maladies, or to the influence of temperament, of individual peculiarities of habit, or of social position; and therefore the diagnosis of no other class of diseases taxes nearly so much the integrity and the patience of the physician.

John Charles Bucknill (1856)

Classification is not the dry exercise of putting things into pigeonboles but the act of creating the holes into which to put things. ${ }^{2}$

Roger Smith (2007)

When Bethlem physician George Savage stated in the 1880s that '[a]ny classification of insanity must necessarily be provisional', ${ }^{3}$ he expressed perhaps the one aspect of classification upon which most Victorian alienists could agree. The classification of mental disease was a hotly contested topic among nineteenth-century physicians-no standard, universally accepted nosology existed, and diagnostic practices, labels, and criteria could differ a great deal between different asylums and hospitals. The British Lunacy Commission attempted to institute a unified system with considerable success, but many physicians continued to favour alternative nosologies, each often with their own idiosyncratic

(C) The Author(s) 2021

Å Jansson, From Melancholia to Depression, Mental Health in Historical Perspective, https://doi.org/10.1007/978-3-030-54802-5_5 
twist. Biomedical models of mental disease dominated in the second half of the nineteenth century, and internal, physiological explanations for melancholia displayed notable coherence. However, such disease models were of little use when it came to diagnostics. While Savage and many of his peers expressed hope and confidence that it would one day become possible to identify and diagnose various forms of insanity according to 'the physiological changes which take place in the nerve centres', 4 they were presently guided in their diagnostic work by the presence or absence of external symptoms. Symptoms of melancholia were observed through the spectacles of physiology, and were shaped through biomedical language, giving prominence to 'depression' and 'mental pain', terms reconceptualised within a modern scientific framework. Another key symptom, 'religious delusions', emerged from patient interviews, which suggested that significant number of melancholics experienced their suffering as punishment from God. Finally, late-nineteenth-century physicians were in particular trained to look for 'suicidal tendencies' in melancholic patients, a problem believed to be so prevalent as to lead one physician to remark that ' $\mathrm{t}]$ he question of the patient being suicidal should never in any case of melancholia be left unconsidered, and the risk of his becoming suicidal should never in any case be left unprovided for' ${ }^{5}$

The belief that a majority of melancholics were suicidal became something of an axiom for late-Victorian asylum physicians, and informed decisions about confinement, surveillance, and treatment of melancholic patients. The term itself emerged as a medical concept through the certificates of insanity that had to be filled out prior to a person's admission to the asylum, and which required a yes or no answer as to whether the suspected lunatic was 'epileptic, suicidal, or dangerous to others'. 6 This information was subsequently transferred into asylum admission records and casebooks, where it was entered alongside various other information about the patient, including the type of disease they were believed to suffer from. When statistics on suicidality were merged with diagnostic figures, these suggested that patients who entered the asylum with the label 'suicidal' on their certificate were far more likely to receive the diagnosis melancholia than other patients, leading to the assumption that all melancholics were potentially suicidal. ${ }^{7}$

Edwin Schneidman, a prominent twentieth-century British psychiatrist, wrote in 1993 that 'suicide is caused by psychache', a term he used to denote 'intolerable psychological pain'. ${ }^{8}$ Perhaps unbeknownst to the author, this phrase echoes the words of nineteenth-century physicians 
who more than a century earlier suggested that melancholia was characterised by a 'psychic ache', 'mental pain', or 'psychalgia' that often led patients to become suicidal. 9 Schneidman's work has formed the basis for more recent research into the relationship between suicidality and mental pain. ${ }^{10}$ In twenty-first-century psy-literature, the close relationship between these two phenomena is apparently taken for granted-intolerable mental pain produces suicidal thoughts and gestures, which sometimes lead to suicide. In the twenty-first century, 'depression'll conjures up similar anxieties about suicidality. Today the term is chiefly used in psychiatry to denote a specific condition-clinical depression or Major Depressive Disorder. The view that this condition carries a significant risk of suicide is accepted across Western medicine, and suicidality is listed as a diagnostic criterion of depression in the most recent editions of both the $D S M$ and the ICD. ${ }^{12}$ Much like the relationship between mental pain and suicidality, the causal bond between depression and suicidal thoughts and actions appears to be taken as self-evident in the present, in medical and non-medical contexts alike. In the Victorian period, there was no illness with this name, but the term was used with growing regularity, primarily to describe the overall mental and bodily state of the melancholic-a pressing down, a dulling of the individual's internal processes of 'nutrition'. Used in this way, the term denoted low mood, inertia, sluggishness, and a general slowing down of bodily functions such as respiration, digestion, speech, and, in some cases, even hair growth. Melancholia was often referred to in nosological literature as the 'state of mental depression', 13 contrasted with 'mental weakness' and 'exaltation'.

Religious delusions were frequently noted as a symptom of melancholia in case notes as well as published literature. Patients who arrived in the asylum and were diagnosed with melancholia commonly expressed profound feelings of guilt. Casebook descriptions tell of 'imaginary' sins committed, of desperate accounts of having 'caused the ruin of' and 'brought shame upon' one's family, of having done such horrible things that one was unworthy of life and must be punished by God. Such expressions of guilt and shame were noted by physicians as 'delusions' of a religious nature, a symptom of mental disease that contributed to melancholic patients' suicidal propensities. To the historian, this symptom illustrates the uneasy yet close relationship between old and new ideas, between spiritual and scientific worldviews and ways of experience. While it is not possible to access the 'true' experience of patients whose stories emerge only as case notes scribbled by their physicians, fears of God's 
punishment and of having brought shame upon one's family through sinful acts must be seen as very much real and present in what was, despite the arrival of modern science, still a largely Christian society, one that placed high value on 'virtues' such as respectability, godliness, purity, and self-help. ${ }^{14}$

As a symptom of melancholia, religious delusions have important contrasts with mental pain. The former were commonly described in case notes, admission documents, and published case studies, but were rarely held up as a defining criterion in textbook definitions of melancholia in the same way as the latter. Mental pain, conversely, was listed as a primary psychological symptom of melancholia in nosological descriptions, but was rarely used as an expressive term in asylum casebooks. From what can be deduced from patient records, it was not a word patients themselves used to talk about their suffering, however it did to some extent feature as a descriptive term in popular language. For Victorian physicians, its usefulness was chiefly as a unifying diagnostic term, a form of shorthand for a range of emotional expressions that asylum physicians took to be the manifestation of psychological pain. While the term itself had spiritual roots, as a medical symptom it was a distinctly modern one, presented in the literature as a physiological state analogous to physical pain.

The terms 'suicidal tendencies', 'depression', 'mental pain', and 'religious delusions' were produced as medical concepts in significantly different ways, through a range of practices and theoretical discussions. They did not emerge at the same time, yet they were mutually reinforcing as descriptive terms of melancholia in the late nineteenth century. The nineteenth-century origins of depression as a mental symptom were considered in Chapter 3. Mental pain has an equally multifaceted history that can be traced in part to early modern religious texts, and in part to physiology, whence it was borrowed as an analogy to describe an emotional state that was perceived as a psychological equivalent of physical pain. The physiological notion of mental pain was more complex, however, as within the new physiological psychology (outlined in Chapter 2), the 'mental' was not merely abstract, but rather understood as the manifestation of physiological processes in the brain. 'Suicidal tendencies', conversely, have more clearly traceable roots, becoming a prominent symptom through the medical certificates of insanity that were introduced in the early decades of the nineteenth century, and through which it became a significant statistical marker for melancholic patients. 
A strong link was forged in the mid-to-late nineteenth century between melancholia and mental pain, depression, and suicidality, and, to a lesser extent, religious delusions. This relationship proved useful in a number of ways, two of which are of particular significance for the present story. First, it played a key role in the nosological reification and standardisation of melancholia in late Victorian medico-psychological literature. Secondly, it offered a useful tool within endeavours to establish psychological medicine (later psychiatry) as a modern scientific discipline and branch of medicine. While this story is focussed on the British context, it is important to note that the standardisation of melancholia was not a strictly domestic development. British physicians read the works of many of their European counterparts; journals were increasingly publishing English translations of foreign (chiefly German, French, and Italian) articles, and ideas and concepts from continental psychiatry were appropriated by British medical psychologists to various extents. In much of the literature, mental pain and depression were held up as a driving force in the suicidality of simple, non-delusional melancholia, whereas religious delusions, particularly a belief in having committed 'the unpardonable sin', was perceived as triggering suicidal intent in people suffering from more severe forms of the disease. This chapter traces these themes through some of the most widely read textbooks of mental disease to emerge in late Victorian Britain by influential medical psychologists such as Henry Maudsley and George Savage, as well as through a number of journal case studies on melancholia published in the last few decades of the nineteenth century.

Central to the standardisation of melancholia was the growing use of medical statistics. The practice of collecting and disseminating patient data in numerical tabular form played a key role in the development of diagnostic practices in the mid-to-late nineteenth century. As will be seen below, in the case of melancholia, this is illustrated by the emphasis placed on suicidality as a symptom of the disease, and by the use of simple key terms to describe a patient's mental state, in particular 'depression'. Historians have drawn upon the large body of asylum statistics that emerged in the wake of the creation of the Lunacy Commission in 1845 in attempts to recreate the Victorian asylum milieu and make sense of the practices and experiences of doctors and patients. However, despite the wealth of existing research into the nineteenth-century lunacy trade and the key role asylum statistics has played in such research, the 
relationship between statistical knowledge and diagnostic theory and practices remains remarkably underexplored. Lunacy administration, statistical collecting and reporting, and the dissemination of clinical data in professional fora such as meetings, journals, and textbooks were key processes in the creation of modern diagnostic categories. Two events in particular facilitated the reification of melancholia as a modern biomedical mental disease with a relatively standardised set of diagnostic criteria. The first of these was the creation of a large body of asylum statistics, as well as increasingly standardised practices for recording symptoms. The second was the emergence of a professional community of medical psychologists, where the question of classification was widely debated, and whence a vast field of published material on nosological and diagnostic questions was emerging. The apparent prevalence of 'suicidal propensities' in patients diagnosed with melancholia serves here as an illustration of the role of administrative practices, chiefly statistical reporting, in the standardisation of melancholia in this period.

Statistics and classification were contentious topics among late Victorian asylum doctors, and lively discussions took place at meetings of the Medico-Psychological Association, as well as on the pages of its periodical, the Journal of Mental Science. Such debates occurred at a time when British alienists were trying to assert the status of their profession as a medical science and academic discipline. Yet, while published articles and textbooks flourished, gradually establishing a solid theoretical framework for psychological medicine, debates regarding asylum admission, treatment, diagnosis, and protection of patients tell of a profession where doubts and anxieties were pervasive and answers few. This chapter begins with a look at the emergence and reification of suicidality as a key symptom of melancholia in the second half of the century, and the role played by statistics in this development. It then maps two of the other key symptoms referred to above-mental pain, and religious delusions - asking how these became part of an increasingly standardised definition of melancholia. Finally, the chapter concludes by discussing the increasingly coherent diagnosis that emerged in the last decade of the century, and the growing medical attention brought to bear upon simple or non-delusional melancholia, a mental state that straddled the boundary between normal and pathological emotions.

The next and final chapter follows the narrative presented here to the pages of asylum casebooks, where the key symptoms of melancholia were seen to manifest in a wide range of acts and expressions. Taken together, 
the last two chapters of this book aim to highlight a tension within psychiatric classification that has been a feature of this kind of knowledge since its inception. They show how, on the one hand, the defining symptoms of melancholia emerged as melancholic patients frequently manifested behaviour that appeared to indicate that they suffered from pathological low mood, painful emotions, and thoughts of suicide. In this way, an increasingly standardised symptomatology can be seen as a response to 'typical' psychological phenomena clustering together in a significant section of asylum populations. On the other hand, however, the perceived need for coherent diagnostic categories, swifter recording practices, and more efficient data collection, created an environment in which a vast range of human acts and expressions were increasingly interpreted as homogenous and made to fit the standard description of melancholia with its key criteria. What these chapters - and the book as a wholeaim to show, then, is that the emergence of a key set of criteria for melancholia that centred on low mood and suicidality was not inevitable, but neither was the diagnosis simply 'constructed'. The production of knowledge about human beings is always a complex, negotiated, multifaceted process, and the creation of modern mood disorders, of which nineteenth-century melancholia was the first, is no exception.

\section{The Problem of Diagnosis in Psychological Medicine}

British textbooks on mental disease greatly proliferated in the last two decades of the nineteenth century, with a growing number of asylum physicians deciding to turn their clinical experience into educational material for students and fellow practitioners. It is difficult to speak of the 'standard' psychiatric textbook as physicians differed a great deal in their approach to mental disease, both in terms of diagnostics and treatment as well as aetiology and internal explanatory models. Nevertheless, a few general remarks can be made about the late Victorian textbook of insanity. First, while aetiology and treatment were undoubtedly significant areas of psychiatric knowledge, far more attention was devoted to diagnostics, that is, the question of how to identify various forms of mental disease. It follows that textbooks were overwhelmingly devoted to classification. Secondly, different asylums deployed different diagnostic systems, with variations being national, regional, local, and even individual 
to each physician. At the same time, a measure of de facto standardisation was gradually instituted, in part as a result of Lunacy Commission recommendations and directives. Textbooks and articles also suggest that a gradual consensus emerged around major diagnostic categories such as melancholia, mania, and general paralysis. Thirdly, the melancholia diagnosis received growing attention in many British textbooks in the last quarter of the century, and diagnostic descriptions became increasingly homogenous, coalescing around mental depression and suicidal tendencies as the core distinguishing symptoms of melancholia. Fourthly, the process of creating and reifying diagnostic categories was complex and contested, depending upon a number of factors: formal guidelines relating to recording practices, statistical tables, growing concern for patient safety and the often conflicting concern for patient liberty, as well as contradictory systems of knowledge (e.g. religious versus scientific, lay versus medical). Equally important, however, were such mundane factors as habit and convenience, made all the more significant with the introduction of standardised printed forms for recording symptoms and diagnoses.

At a time when an increasing number of asylum physicians chose to publish books and articles on their research and clinical experience, nosological concerns were at the forefront of professional debates. What kind of system one adhered to was a statement about one's epistemological approach to insanity-as Maudsley had suggested in 1867, a correct classification system was one that was grounded in scientific knowledge and 'in conformity with nature'. ${ }^{15}$ But what 'nature' suggested about the classification of mental disease was not universally self-evident. A rapidly expanding catalogue of publications on insanity meant a rapidly growing number of different systems. From the multitude of nuances and more marked differences between nosologies, three ways of labelling and categorising insanity can be identified that were particularly common: classification according to stages (e.g. acute or chronic), classification according to causes (e.g. alcoholic insanity, puerperal insanity, climacteric insanity), and classification according to observable symptoms (e.g. melancholia, mania, general paralysis). Many physicians used a combination of all three, rather than selecting one, and all three systems prevailed in some form or another throughout the Victorian period. What is perhaps most telling about the different systems proposed is that the one thing physicians largely agreed on was the difficulty in translating clinical 
observations into consistent theoretical frameworks. To label and categorise the multitude of human activity that was met with on asylum and hospital wards was a challenging task. Henry Monro noted as much in the 1850s:

All who have charge of asylums must well know how very different the clear and distinct classification of books is from that medley of symptoms which is presented by real cases, where each case seems to bear as peculiarly its own idiosyncrasies of detail, as hardly to allow of very minute division. ${ }^{16}$

Nevertheless, despite their own admission as to the problems inherent in trying to attach strict medical labels to the unpredictability of human emotions and actions, Victorian medical psychologists remained persuaded of the necessity and usefulness of classification, setting the tone for psychiatric diagnosis ever since.

\section{Classification and Medical Statistics}

While many British physicians were keen to add their own version of popular nosologies to the ever-growing catalogue of systems, a universal system of classification was proposed in the 1844 report of the Metropolitan Commissioners in Lunacy to the Lord Chancellor. The Metropolitan Commission had been set up in 1828 by the Madhouses Act to oversee the management of lunatic asylums and licensed houses in London and surrounding areas, ${ }^{17}$ with its authority extended to all of England and Wales in 1842. ${ }^{18}$ The nosology presented in the report brought together old and new categories, suggesting nine different types of mental disease: mania (divided into acute, ordinary, and periodical), dementia, melancholia, monomania, moral insanity, congenital idiocy, congenital imbecility, general paralysis, and epilepsy. The report remarked that melancholia, monomania, and moral insanity were 'sometimes comprehended under the term Partial Insanity', and further suggested that 'delirium tremens' might be considered as an additional category to those stated. Despite numerous individual attempts by physicians to put forward their system of classification as the most 'correct' and 'scientific', a somewhat simplified version of the nosology endorsed by the London Commissioners proved enduring in the context of asylum diagnostics. Its 
apparent popularity can be explained in large part through the requirements placed on asylum medical officers by the Lunacy Commission in the second half of the century, as will be seen below.

In its 1844 report, the Metropolitan Commission emphasised the importance and value of statistics in the management of asylums. The report lamented the inconsistent nature of existing figures, which were perceived as incomplete and fragmentary, failing to give an accurate account of the number of lunatics residing in Britain. Following from this, an inquiry was undertaken, whereby the managers of asylums and licensed houses in England and Wales were asked to supply their latest figures, with the investigation being extended 'to a certain degree, to Scotland and Ireland'. In order that such inquiries could be carried out more efficiently and comprehensively in the future, the Commissioners proposed the nationwide introduction of "certain forms of Registers and Medical Books, to be kept at all Asylums, with a view to the preparation of Statistical Returns, at stated and uniform periods'. ${ }^{19}$ When the national Lunacy Commission was created in 1845 (see below), such a system was rapidly instituted, and had significant and lasting consequences for how melancholia was defined and diagnosed.

The classification and diagnosis of melancholia took place against the backdrop of a wider context of a culture increasingly preoccupied with categories and numbers. ${ }^{20}$ The natural historians of the eighteenth century, such as Linnaeus and Blumenbach, had cemented classification as a central component of their work; to know the living world, one must organise it-name, label, and categorise it. When Linnaeus put together his Systema Naturae, he considered his own work to be that of an identifier, whose task it was to find the correct boxes for each thing existing in nature. ${ }^{21}$ As Foucault has suggested, however, the birth of modern classification 'was not an age-old inattentiveness being suddenly dissipated, but a new field of visibility being constituted in all its density'. ${ }^{22}$ In the nineteenth century classification became a totalising practice; "[p]eople classified, measured, and standardized just about everything - animals, human races, books, pharmaceutical products, taxes, jobs, and diseases' ${ }^{23}$

Classification of mental disease was helped by another nineteenthcentury favourite preoccupation: statistics. ${ }^{24}$ Terrence Murphy has traced the early years of modern statistics among French scientists such as Condorcet, who hoped to establish 'a science of decision making', a tool with which decisions in political society could be made according to calculated probability and thus protected from rash judgments motivated 
by passion. ${ }^{25}$ Numbers would tell people which course of sociopolitical action to take by suggesting probable consequences of various options. While Condorcet did not complete his visionary project of a decisionmaking science, the foundation was laid, and others continued to build upon it, most notably Laplace. ${ }^{26}$

The theory of probability was picked up and utilised by Philippe Pinel, who had taken over the running of Paris' large asylums during the first republic. Pinel believed that persistent recording of data that allowed the medical scientist to compare and contrast symptoms and their treatments would result in improved therapeutics and consequently better outcomes for those diagnosed with various forms of insanity. He separated medicine into two branches, nosography and therapeutics, suggesting that probability theory applied only to the latter. ${ }^{27}$ Some decades later, however, it became productive of the former. In the second half of the century, reasoning about the regularity of events became paramount to the diagnosis of melancholia, and in particular to the almost universal belief that suicidality was a defining symptom of the disease. According to statistics produced by British asylums, expressions and actions collated under the term 'suicidal tendencies' were seen to occur in the disease with frequent regularity, resulting in the expectation that a diagnosis of melancholia meant the likely presence of suicidality. This assumption significantly affected how such patients were cared for-if melancholic patients were expected to harbour suicidal intentions, strict precautions must be taken to ensure that they were unable to injure themselves. It also altered the interpretation of symptoms at the moment of diagnosis. 'Suicidal tendencies' became central to the ontology of melancholia-but this was not a simple or inevitable development. It relied upon, and was produced by, a set of legal guidelines generating changes to recording practices and vast amounts of new kinds of statistical data.

\section{Asylum Statistics and the Standardisation of Recording Practices}

Wynn's Act of 1808 had allowed for county asylums to be established as institutions providing for pauper lunatics. ${ }^{28}$ In the subsequent years, admission to licensed private houses came to require legal documentation certifying the mental state of the person taken into care, a provision that was eventually extended to pauper asylums. ${ }^{29}$ As noted above, institutions in the Greater London area had since the late 1820s been subject 
to inspections and directives from the Metropolitan Commission, which had its powers extended to oversee the running of asylums throughout England and Wales in the last two years of its existence. When the Lunatics Care and Treatment Act and Regulation of Asylums Act ${ }^{30}$ (hereafter 'the Lunacy Acts') were passed in 1845, these constituted to a degree 'a consolidation of "lunacy reform"' begun at the end of the previous century. ${ }^{31}$ Such earlier developments can also be seen as the first bricks in the bureaucracy that was rapidly constructed in the aftermath of the Acts. Every county in England and Wales was compelled to erect its own pauper asylum within three years. The Acts moreover created a permanent body, the Lunacy Commission, to oversee the implementation of the Acts. ${ }^{32}$ While the practice of collecting and disseminating statistical information pertaining to asylum populations had begun under the administration of the Metropolitan Commissioners, with the creation of its successor body this process became vastly more comprehensive, organised, systematised, detailed, regular, and wide-reaching. In the first instance, the yearly reports that asylums were required to submit to the Commission produced a wealth of statistical information about the people residing in these institutions. In addition to this, almost immediately after the initial stipulations of the Acts had come into force these were built upon through a relentless flow of circular letters from the Commission to the asylums requesting various kinds of information, from 'a copy of your present Diet Table'33 to whether post-mortem examinations were performed on a regular basis. ${ }^{34}$

The Lunacy Acts had set out detailed instructions for the management of asylum populations, including the various administrative tasks required, and attached to the main documents were a number of appendices with templates for some of the paperwork relating to admission and care of lunatics under the new law. Of primary concern for the present story are the medical certificates of insanity and accompanying reception orders, as well as the asylum admissions registers and casebooks. The 1845 Lunacy Acts extended the scope of medical certificates and explicitly set out their legal framework. The Acts stipulated that a patient admitted to the asylum must be legally certified as 'a lunatic [or an insane person, or an idiot, or a person of unsound mind] and a proper person to be confined' 35 They distinguished between private and pauper patients; for the latter one certificate was enough, while for the former two (signed by different physicians) were required. ${ }^{36}$ Appendices to the Acts provided doctors with a clear template for the medical certificate and reception order, the 
latter listing the various 'particulars' required, such as 'age', 'sex', 'place of abode', whether this was the patient's 'first attack', and whether he or she was 'epileptic', 'suicidal', or 'dangerous to others'. ${ }^{37}$ In the case of private patients, this statement was often filled out by a spouse, relative, or friend, while reception orders belonging to pauper patients were customarily filled out and signed by a magistrate or workhouse official. Upon arrival at the asylum, the data on these forms would be transferred to the admissions register. Asylum physicians were legally required to add a diagnosis to this information within a week of admission. ${ }^{38}$

Following the establishment of the Lunacy Commission, asylum physicians were obliged to compile yearly reports on the state of their institutions, including statistics on a large number of aspects pertaining to the asylum population. This meant that for the first time a large body of data was created from which one could extract virtually any thinkable piece of information about every county asylum in Britain, ${ }^{39}$ organised in tabular numerical form. Asylum physicians, the county Board of Visitors, ${ }^{40}$ and Lunacy Commissioners were able to learn from such figures how many men and women resided in each asylum, what proportion of these were married, single, or widowed, which professions and religious persuasions were represented among them, the average age of patients, the most common form of mental disease (usually mania), how many people were admitted and discharged each year, how many patients died in the asylum and how many autopsies were performed, what treatments were administered, and so on.

One of the provisions set out in the Lunacy Care and Treatments Act of 1845 was that each asylum had to keep a casebook where detailed information about each patient's condition was to be entered at regular intervals. The instructions of the Act had been relatively vague regarding the casebook, stating merely that such a book should be kept by every asylum and that the presiding physician should in this book 'from time to time make entries of the mental state and bodily condition of each patient, together with a correct description of the medicine and other remedies prescribed for his disorder'. ${ }^{41}$ Shortly after the Lunacy Acts had come into force, however, the secretary of the Commission sent out a letter to all county asylums with guidelines on the use of the casebook, which were subsequently also incorporated into an 1853 legal amendment. The Commissioners left the format of the casebook to be decided by each superintendent, since a strict template 'might tend to cramp and fetter the Practitioner in his detail of individual cases'. However, clear 
directives were provided concerning the content of the casebook. Physicians were instructed to enter much of the basic information derived from the admissions register, such as name, sex, and occupation of the patient. Secondly, a detailed description of the patient's external bodily condition, and of respiratory and visceral organs, was to be given, along with a pulse and state of the tongue and skin. Thirdly,

A description of the phenomena of mental disorder which characterize the case; - the manner and period of the attack; - with a minute account of the symptoms, and the changes produced in the patient's temper or disposition; - specifying whether the malady displays itself by any, and what, illusions, or by irrational conduct, or morbid and dangerous habits and propensities' ${ }^{42}$

Bearing in mind, then, that the Lunacy Acts had already stipulated that for each patient a diagnosis had to be entered; this diagnosis also had to be accompanied by a detailed description of the disease, listing emotional and intellectual symptoms, as well as noting whether the patient was considered to harbour any 'morbid propensities'.

With the Lunacy Commission's strong emphasis on the importance of collecting and disseminating statistics, asylum physicians inevitably devoted a considerable amount of time and energy to the gathering of such data, and consequently also to discussions about how to best go about this task. Statistics became a central topic of discussion at the annual meetings of the Medico-Psychological Association. Unlike in Germany, where a number of different psychiatric associations and journals had been created at this time (sometimes in opposition to each other), ${ }^{43}$ the Medico-Psychological Association was the chief forum within which British asylum physicians could meet and discuss their trade and their nascent discipline. Its professional periodical, the Journal of Mental Science, offered a space for physicians working in the field of psychological medicine to present their research and partake of and comment on the work of others. The Journal of Mental Science moreover published the proceedings from the Association's quarterly and annual meetings.

In 1864, the members of the Association appointed a committee consisting of Henry Maudsley, C. Lockhart Robertson (of the Sussex County Asylum at Hayward's Heath), and John Thurnam (of Wiltshire County Asylum) whose task it was to look into the question of data collection in the asylum, and consequently 'to draw up a series of tables, 
and a form of register which might be the basis of a uniform system of asylum statistics'. The intention was that 'these tables be submitted to the Commissioners' who would be 'asked to sanction and promulgate them'. The Committee of Asylum Statistics proposed six tables, revised from those already in use and intended to homogenise and streamline asylum statistics. The tables concerned statistics on admissions, discharges, and deaths, but did not include columns for specific diagnoses. ${ }^{44}$ At the Association's annual meeting in 1867, the Committee was pleased to report that twenty-six English asylums, two Scottish, and one Irish had adopted the new tables. ${ }^{45}$ These had also received the blessing of the Commissioners in Lunacy, who praised the initiative of the Medico-Psychological Association in facilitating the collection of numerical data from asylums around the country, and who had endorsed the new tables in their annual report the previous year. ${ }^{46}$ The Commissioners suggested that in addition to the existing tables, it would also be 'desirable' to draw up uniform tables showing 'the ages of patients on admission, the duration of the exiting attack, and the form of mental disorder under which they labour', expressing 'hope' that 'the medical officers of asylums may see the great importance of coming to some agreement upon these points'. ${ }^{4}$

The Committee on Asylum statistics proposed three additional tables that partially redressed the Lunacy Commission's concerns. New forms asked for causes of insanity to be listed, as well as length and number of attacks, and causes of death. The latter included indications of the type of disorder that the deceased patient had suffered from with the heading 'maniacal or melancholic exhaustion or decay' listed alongside other causes such as 'epilepsy', 'apoplexy', and 'general paresis' ${ }^{48}$ However, the Medico-Psychological Association failed to adopt a uniform system of classification of mental disease; not surprisingly, perhaps, considering the vastly conflicting and diverse opinions of its members on this matter. In the 1879 edition of his textbook, Henry Maudsley remarked that 'as many as forty or fifty different systems of classification have been propounded', ${ }^{49}$ and the problems attached to developing a correct system were, he suggested, the same as in the 1840s and 50s: 'until we know exactly the obscure constitutional conditions which are at the bottom of the differences of symptoms - of which we know nothing yet - we cannot dispense with a symptomatological classification'. ${ }^{50}$ George Savage echoed this claim a few years later, adding that he himself chose to use the system that was most 'convenient' from a clinical point of view. ${ }^{51}$ 
The problem of uniform classification was not in the end to be resolved through theoretical discussions in the forum of the MedicoPsychological Association or in textbooks or journal articles. Rather, the instituting of practices aimed at facilitating the collection and coherence of medical statistics had the effect of producing a de facto standardised nosology. While physicians themselves were unable or unwilling to agree on a nationwide system of classification, the increasing number of directives issued from the Lunacy Commission regarding the collection of asylum statistics encouraged the use of certain specified categories. In the 1870s the Lunacy Commission introduced pre-printed forms for recording the different types of mental disease in the asylum. As noted above, medical officers were already required by law to record a diagnosis in the casebook within one week of a patient's admission, and this information was included in each asylum's annual report to the Commission. However, with different nosologies favoured by different physicians, cross-comparison between asylums in this area was blatantly problematic. In an attempt to redress this, attached to a circular letter sent out to all asylums and licensed houses in 1876 was a pre-printed form for the main register of patients, with five columns provided under the heading 'form of mental disorder': mania, melancholia, dementia, congenital insanity, and 'other forms of insanity' (general paralysis was also listed, but as a symptom alongside epilepsy rather than as a separate disease entity). ${ }^{52}$

While the implementation of directives from the Commission necessarily varied between asylums, and while some physicians were more likely to make frequent use of the last column than others, the Commissioners' persistent attempts to derive uniform, comparable data from asylums were crucial in shaping what kind of data was recorded. Melancholia was a term that had existed in medical literature in some form or another since antiquity, it was recognisable and came, increasingly, with a number of well-known features attached to it. The two most easily distinguishable types of insanity on the asylum wards were generally considered to be melancholia and mania. That the Commission's pre-printed table listed these two categories was significant in ensuring their continued usage on the wards. Consequently, a sample survey of statistics from a number of asylums around the country between the 1860s and 1880s indicate that the two most common forms of mental disease diagnosed were mania and melancholia (in that order). ${ }^{53}$ While physicians continued to battle out their disagreements over classification in journal articles and at professional gatherings, it can nonetheless be concluded that by the 1870 s the 
beginnings of a standard nosology existed in Britain, one which held melancholia to be a distinct form of mental disease. Mid-to-late Victorian physicians offered concise diagnostic descriptions of melancholia which, in contrast to those of earlier writers like Conolly, centred upon the definition of a disease entity, rather than of the person(s) seen to embody the illness. Despite persisting disagreements over what kind of system should be used, the nosological status of melancholia was conversely strengthened and homogenised during this period.

\section{Melancholia and Suicidal Tendencies}

While physicians might have preferred to use their own system of classification, they were nevertheless keen on using the statistical data collected for their annual reports to the Commission in their own theoretical discussions on mental pathology. Such information overwhelmingly suggested that a majority of melancholic patients harboured suicidal tendencies, and of all patients admitted to the asylum, the majority of those who received the 'suicidal' label were diagnosed with melancholia. In the first half of the century physicians across Europe had become increasingly preoccupied with suicide and insanity, as illustrated by Forbes Winslow's popular The Anatomy of Suicide published in 1840. Winslow's work was a comprehensive lesson in suicide statistics, making the most of the science of numbers as a tool for explaining why people would commit what had long been an unforgivable sin but which was now more frequently perceived as the product of an unsound mind. Winslow, Esquirol, Falret, and other early nineteenth-century medical scientists with an interest in suicide had two things in common. First, they were almost exclusively concerned with completed suicides, and the statistics they compiled and/or drew upon were of people who had died (presumably) at their own hands. The adjective 'suicidal' was a recent addition to the English language. It was used sparingly in the first few decades of the century, but by the late 1800s it had become a standard diagnostic term. Secondly, they paid only marginal attention to suicide in relation to melancholia.

This was in stark contrast to their late nineteenth-century successors. In the last two decades of the nineteenth century, 'suicidal tendencies' became a defining symptom of melancholia. ${ }^{54}$ This shift can in part be attributed to one of the obligatory questions on the reception order which accompanied the medical certificates of insanity. As noted 
above, the reception order required a yes or no answer as to whether the patient to be admitted was 'suicidal'. Once the suicidal label had been affixed to the individual certified as a lunatic, it followed them into the asylum casebook, where it was noted together with other symptoms, bodily condition, and diagnosis. This information became part of each asylum's annual statistical reports, which indicated that a significant portion of patients were considered suicidal. This category of patients became a particular concern of the Commissioners in Lunacy; suicidal patients posed a threat to the reputation of each asylum and thus to the competency of the Commission.

Less than a decade after the passing of the Lunacy Acts, Thomas Brushfield, medical superintendent at Parkside Cheshire County asylum (and later at Brookwood in Surrey), concluded from his annual data that 42 out of the 102 patients admitted to Parkside that year were recorded as having exhibited 'suicidal impulses' ${ }^{55}$ Alluding to the significance such figures were rapidly taking on for physicians and Commissioners alike, he suggested that ' $[\mathrm{t}]$ his class at all times causes great anxiety to the medical officers, as notwithstanding the greatest vigilance on the part of the attendants, fatal cases will sometimes occur; no instance of the kind has, however, happened during the past year' ${ }^{56}$ Parkside was representative of the norm. The figures reported to the Lunacy Commission and the Scottish Board of Commissioners from British asylums each year showed a persistently high (and rising) level of 'suicidal propensities' in patients diagnosed with melancholia.

Anxieties generated by asylum statistics led to an increasing focus on prevention. Patients considered to harbour suicidal tendencies were assigned a pink caution card to be worn at all times, and extra night duty staff were deployed to ensure that suicidal patients were never left unsupervised. ${ }^{57}$ Concerns about how to best care for suicidal patients also led to a revival in support for mechanical restraint, a practice that had been rejected by the new 'humanitarian' practice of moral treatment that had emerged at the turn of the nineteenth century. As the relationship between melancholia and suicidality gradually became circular and mutually constitutive, the necessity of restraining such patients for their own good was increasingly presented as a key argument for having melancholy and suicidal patients admitted to the asylum. Physicians were expected to treat patients and keep them safe, meaning that a suicide within the walls of an asylum, or resulting from an escape, was a black stain on that institution's reputation. At the same time, however, there was political 
opposition to restraint, as well as to arbitrary confinement. Tension also existed between the workhouse and the asylum, with disagreement over who should ultimately be responsible for the treatment of pauper lunatics. The relationship between these two institutions had consequences for the emergence of suicidality as a medical concept and defining symptom of melancholia. For a troublesome patient to be transferred from the (usually more crowded and comparatively scarcely resourced) workhouse infirmary to the asylum, the staff at the former generally had to be able to demonstrate that the patient could not be properly cared for or managed in the workhouse. This was most easily done by affirming that the patient was a danger to other residents, or to themselves-in other words, 'suicidal'.

Concerns about a patient's suicidal intent were not, however, alleviated by their presence in the asylum. The Commissioners in Lunacy, whose responsibility it was to ensure that Britain's lunatics were properly cared for, were anxious about potential suicides in the asylum, and consequently instructed medical officers to ensure that such patients were being appropriately watched over. Death by suicide was, in fact, rare in the asylum; nevertheless, preoccupation with statistics over suicidal tendencies grew steadily in the decades following the 1845 Acts. The Commissioners took measures to ensure that concern over and precautions against suicidality were a priority in every asylum by repeatedly emphasising the matter in their correspondence with asylum medical officers. ${ }^{58}$

There was, however, some controversy surrounding the suicidal label, particularly in regard to the reliability of asylum data on the prevalence of suicidality. Bethlem superintendent George Savage questioned the justification to keep suicidal patients under constant surveillance on the basis that the statistics on suicidality were flawed. Many patients who were given the suicidal label upon certification or admission were not, he argued, 'actively suicidal'. While 'many speak of suicide', he said, 'but few really determine to attempt it' ${ }^{59}$ Consequently, he concluded that 'I do not think that more than five per cent of our admissions are "actively suicidal"' ${ }^{60}$ Many of his peers were equally critical of the validity of statistics. While the members of the Medico-Psychological Association had made efforts to comply with the Lunacy Commission's requirements for the recording and collecting of statistical data, many physicians expressed scepticism about the usefulness of such numerical information. At the 1865 annual meeting of the Association, a number of its members became involved in a discussion about the 'fallaciousness' of statistics, which led Henry Monro to declare that 'of all the humbugs of the present day 
that of statistics is the greatest'. ${ }^{61}$ Most of the members who participated in the discussion were in agreement that figures collected were too diverse, fragmented, and arbitrary for any meaningful cross-comparison to be made between asylums. Maudsley summed up what appeared to be the general sentiment of the group when he ventured that numerical data was 'generally so insufficient as to be not only not useful but positively to mislead. Strictly comparable cases are not taken; conditions and circumstances of importance are neglected, or are not observed as they should be, so that the statistics lose all their value, and are positively used for the purpose of inculcating what is not true'. While he suggested that statistics could indeed be useful 'if properly collected', he implored his peers to remember that they 'never do establish laws or exact facts of any kind'. ${ }^{2}$ The sciences of classification and statistics were undoubtedly embraced by nineteenth-century medical psychologists, but it would be wrong to assume that the adoption of these practices occurred in an uncontested and unproblematic way. On the contrary, the role and the reliability of statistics in the diagnosis and treatment of mental disease was a topic of contention among Victorian physicians.

Brushfield, who had moved to Brookwood asylum in Surrey in 1869, echoed Maudsley's warning in one of his annual reports to the Lunacy Commission. He suggested that the flawed nature of statistics on suicidal patients were due to the way this data was collected. ${ }^{63}$ As noted above, the reception order accompanying the medical certificates of insanity required an answer to the question of whether the person to be certified was 'epileptic, suicidal or dangerous to others'. Unlike the 'facts indicating insanity' on the medical certificate, which was filled out by a physician, the information requested on the reception order was usually provided by a relative, friend, or workhouse official. Moreover, the format of the two documents differed significantly. If reliable data was to be collected, he argued, these discrepancies had to be addressed. ${ }^{64}$ In their present state, the forms resulted in incorrect information about a patient's mental state, in particular relating to suicidality, as the forms obscured a distinction between patients who were 'a danger to themselves', conflating the patients with 'no suicidal motive' who nonetheless 'imperils his own life by various acts', and those with genuine 'suicidal tendencies'. He illustrated the first category with the case of a woman who was admitted to the asylum after having 'cut her left hand off because she thought it was Scripturally wrong'. While this patient was described 
as 'suicidal' on her certificate, the label was incorrect since her motive for mutilating herself was 'a non-suicidal one'. ${ }^{65}$

When it came to suicidal melancholics, however, Brushfield was clear, declaring that 'I would urge upon all medical practitioners the necessity of regarding all cases of melancholia as having suicidal tendencies'. Such tendencies could be deduced from patient interviews as well as from conversations with friends and relatives, and these should, he argued, be cited on the medical certificate under the section requesting the 'facts indicating insanity'. ${ }^{66} \mathrm{He}$ went on to suggest what such facts might consist of Suicidal tendencies in melancholic patients could manifest, he argued, in the expression of 'melancholy views', especially of a religious nature, such as believing oneself to have committed sins, or more overtly in the form of attempts at self-destruction. ${ }^{67}$

The question on the reception order requiring a yes or no answer to whether the lunatic was suicidal merged a wide range of acts and behaviours into this category. This homogenising process was at the same time productive of a wealth of purported psychopathological knowledge about the people to whom these categories were seen to apply. As will be seen in Chapter 6, a vast number of acts and expressions were collapsed into the single term 'suicidal', such as talking about death, refusal of food, thoughts of guilt and damnation, fear of persecution, and self-inflicted bodily harm. Increasingly exact knowledge was produced by allowing standardised categories to obscure the eclectic nature of human life that terms like 'suicidal' were deployed to explain. By mapping the work done by standardised forms and recording practices we can learn something about the process whereby 'a seemingly neutral data collection mechanism is substituted for ethical conflict about the contents of the forms'. When this occurs, then, 'the moral debate is partially erased. One may get ever more precise knowledge, without having resolved deeper questions, and indeed, by burying those questions' ${ }^{68}$ Through the recording practices and data collection in asylums following the creation of the new bureaucracy presided over by the Lunacy Commission the term 'suicidal' simplified and obscured the complex and varied; it neutralised the contested and conflicted.

When statistical data from reception orders and medical certificates was merged with information derived from asylum case notes and registers, this showed that the 'suicidal' label was applied more frequently to people diagnosed with melancholia than to any other disease category. This facilitated the argument that melancholics were by far the most suicidal of all 
lunatics. Eventually this argument became self-perpetuating, and physicians began to suspect suicidal tendencies in melancholic patients even when these were not openly manifested. In this way, suicidality went from being a marginal symptom of melancholia early in the century, to becoming a key defining criteria of the condition on par with 'depression'. Suicidality and melancholia became mutually constitutive: increasingly the presence of one was enough for the 'discovery' of the other.

\section{The Historical Roots of 'Mental Pain'}

While the emergence of suicidality as a defining symptom of melancholia was closely tied to the medical certificates of insanity and the growing body of asylum statistics, 'mental pain' had rather different origins. Mental pain was conceived of as analogous to somatic pain, and like the latter had a solid biomedical explanation and trajectory. However, the patients to whom the melancholia diagnosis was affixed appeared to speak of their pain as something quite different. Patients' own expressions of sin and guilt, and stories offered by distressed relatives and spouses, were interpreted by physicians and presented in medical language. This practice of interspersing curt keyword descriptions of symptoms with verbatim patient quotations created a language of diagnosis and classification in which medical and lay descriptions were awkwardly fused. This is equally apparent in descriptions of religious delusions as a symptom of melancholia, as will be seen below. Both mental pain and religious delusions as symptoms of melancholia illustrate the tension between spiritual and scientific worldviews in the period, reflecting a culture where the two were simultaneously conflicting and closely intertwined. ${ }^{69}$ In the late nineteenth century the term mental pain was deployed by physicians as a predominantly biological description of melancholic suffering, but its meaning had gradually shifted from earlier spiritual language to eventually enter medico-scientific nomenclature through early modern medical writings that more comfortably straddled the emerging divide between scientific and spiritual conceptions of the human condition.

Much existing scholarly work on the history of pain is concerned with the medieval and early modern periods ${ }^{70}$; however, a rich literature has begun to emerge that seeks to historicise nineteenth- and twentiethcentury conceptions of pain. ${ }^{71}$ Javier Moscoso's Pain: A Cultural History (2012) addresses ontological evolutions of pain from medieval Christian 
conceptions to modern scientific ones. With the advent of nineteenthcentury scientific medicine, he perceives a shift whereby the sufferer's 'private experience' was objectified through new ways of constituting, explaining, and labelling pain. In a context where pain, like so many other aspects of society, had to be measurable, there was no room for 'unjustified claims and disproportionate laments' from the suffering subject. 'As opposed to introspection and testimony', he argues, 'the new science of the intimate sense had to be rooted in physiology and physics'. ${ }^{72}$ What emerged within psychological medicine, however, was a more complex picture. The circular relationship between clinical practice and theoretical discussions created a space within which psychological pain was constituted as physiological, and as an object that could be recorded and measured in statistical tables. Yet doctors were only able to access the nature of this mental pain through patient testimony. The trouble of recording and diagnosing the abstract pain of emotional life lay in the fact that its chief manifestation was through language, which revealed nothing about the internal neural processes that were believed to be the 'real' source of patients' mental pain.

An important consequence of medico-psychological perceptions of the mental suffering that melancholic patients expressed as one having traceable (but regrettably not observable) physiological roots, was that any references to God, sin, and divine retribution were translated into patient journals and medical literature as 'religious delusions'. However, when mapping the shifting meanings of mental pain from earlier non-medical usages to its later emergence as physiological metaphor and finally a psychological phenomenon with an explicable biological basis, the source of the melancholic patient's perception becomes apparent. In a series of letters written at the turn of the eighteenth century, clergyman and religious thinker John Norris and philosopher Mary Astell ${ }^{73}$ debated the relationship between mental pain and sin. Astell asserted that 'I cannot form to my self any Idea of Sin which does not include in it the greatest Pain and Misery'. Committing a sin against God would, she argued, result in mental pain. In much the same way as 'a musical Instrument, if it were capable of Sense and Thought, would be uneasie and in pain when harsh discordant Notes are play'd upon it; so Man, when he breaks the Law of his Nature, and runs counter to those Motions his Maker has assign'd him...must needs be in Pain and Misery'. ${ }^{74}$ For Astell, then, to act against God and nature was to act sinfully and to cause pain. A similar understanding of mental pain as sin was expressed a few years later by 
another English clergyman, Richard Fiddes, who in his Fifty Two Practical Discourses on Several Subjects (1720) explained that 'what I principally here intend, by mental Pain, is, that Anguish and Remorse of Mind, which Sinners so naturally feel, and all of them, more or less, when they call their own Ways to remembrance, and reflect upon their sins. ${ }^{75}$

It is significant to note the unambiguous way in which this point of view established a causal trajectory between unnatural and ungodly conduct and the experience of mental pain. A century and a half later, British physicians turned this argument on its head, suggesting that the mental pain felt by melancholics would render the act of suicide-the ultimate crime against God and nature-both 'logical' and 'natural'. Victorian medical psychologists were keen to assert the irrelevance of moral judgement when explaining the symptoms and causes of mental disease, but their case notes allude to people for whom the moral implications of their painful emotions were a great source of distress. The association between religion and mental pain was rooted in a centuriesold spiritual worldview where Man's duties to God were foremost, and where to act against divine law was for faithful Christians an unequivocal source of pain and despair. It is not surprising that a relationship between religious morality and emotional distress that had endured in some form or another for centuries appeared to prevail among melancholic patients against medico-scientific explanations that were, by comparison, embryonic.

The medico-psychological understanding of mental pain that emerged in the nineteenth century arose chiefly from a different epistemological context, that of experimental physiology, yet the two conceptions remained in a close and often antagonistic relationship throughout the period. It should also be noted that in early modern literature, spiritual and medical conceptions of pain were not mutually exclusive, and such perceptions were not simply erased with the advent of physiological psychology in the nineteenth century. It follows that early modern ideas about mental pain as an 'evil' or as 'sin' cannot be simply excluded from late nineteenth-century meanings of the term. ${ }^{76}$ Moreover, the adoption of mental pain as a medical phenomenon was not a straightforward production of nineteenth-century physiological psychology, but, like the creation of modern physiology itself, a gradual process where old and new terminology was fused to espouse medical theories about body and mind set in current explanatory frameworks. ${ }^{77}$ 
When mental pain entered the realm of nineteenth-century physiological psychology and psychological medicine, then, it did so from an eclectic past. Victorian medical scientists used the term in specific ways to explain the psychological suffering that was the manifestation of cerebral irritation producing a state of disordered emotion. Earlier chapters showed how the perceived 'irritation' of the cerebral nerves would over time affect the 'tone' of the brain, causing painful emotional and ideational associations to occur. Andrew Hodgkiss has traced the history of 'pain without lesion' in nineteenth-century European medicine, investigating precisely this conception of how mental pain was perceived to materialise. He pays particular attention to how ideas about cerebral irritation and reflexive action functioned to constitute a physiological model for pain without traceable organic cause in the work of Johannes Müller, Wilhelm Griesinger, and Thomas Laycock. Key to making sense of nineteenth-century psycho-physiological conceptions of pain without lesion is, Hodgkiss argues, the argument, proposed by Laycock, that mental sensations alone were enough to cause irritation of the nerves. ${ }^{78}$

Central to psycho-physiological ideas about mental pain favoured by British medical psychologists in the late nineteenth century was a belief that such pain functioned in much the same way as physical pain. In a similar manner to cerebral irritation and psychological reflex action, mental pain in nineteenth-century physiological psychology held the ambiguous status of being at once metaphorical and literal. Experimental data concerned observable bodily reactions, and knowledge derived from empirical research was extrapolated and analogously applied to speak about mental operations - that which could not be observed. At the same time, however, analogies were believed to represent what was actually occurring in the brains of people. Terms like 'irritation', 'reflexion', 'tone', and 'pain' when applied to speak of the mind were seen as explicating cerebral processes as well as psychological operations. This can be seen in Griesinger's discussion of mental pain in the second, extended edition of his textbook. ${ }^{79}$ He suggested that it resulted from mental irritation, both of the kind that manifested in psychological exaltation, and of its opposite, depression, and that such pain could be triggered by external as well as internal factors. Citing recent experiments by German physiologist Moritz Schiff, ${ }^{80}$ Griesinger held that the sensation of pain 'could only be transmitted through the grey substance', suggesting that pain originated in the brain. This explained, he argued, how mental pain could arise endogenously, through a 'special irritation' of the cerebral tissue. ${ }^{81}$ 
Older meanings did not simply vanish, however, and they continued to facilitate conceptions of self for the melancholic patients to whom this label was affixed. As will be seen below, where patients communicated a spiritual suffering, their physicians saw a physiologically constituted pain that manifested as a psychological phenomenon. Nevertheless, mental pain was a useful medical concept in the building of a solid biomedical foundation for mental disease. The sensation of pain was an important tool in physiological experiments on nervous function, particularly in its relationship with automated muscular reactivity. It was helpful if one could show that the same connection existed between psychological pain and involuntary action. Such arguments became problematic towards the end of the century, however, when physicians focussed their attention on the perceived prominence of suicidal actions in non-delusional melancholics, as will be seen below. It was more difficult to maintain that suicide, suicidal attempts, and suicidal tendencies were morbid impulses (as was often the case earlier in the century) when the subject was believed to be capable of rational thought. In this context, then, suicidality was reconceptualised, so that mental pain and depression came to function as 'logical' and 'rational' causes of suicidal intent in people perceived to suffer from simple (non-delusional) melancholia.

\section{'Religious Delusions' and 'The Unpardonable Sin'}

While 'religious delusions' was not put forward as a defining characteristic of melancholia to the same extent as depression, suicidality, and mental pain, this symptom nevertheless featured frequently in published case studies and descriptions of the disorder. Much like the other key symptoms of melancholia, religious delusions became a standardised term that physicians could use in their work that would make sense to their peers and students. These symptom descriptions recorded by physicians in asylum casebooks and drawn from their interpretations of what patients communicated reveal much about the tensions between lay and medical conceptions of self, and about the negotiations that took place when medical scientists attempted to label and categorise their patients' disordered emotionality. Only the medico-psychological expert could correctly interpret this chaos of human experience; it followed that patients' perceptions of their own misery were, for the most part, wrong. Thomas Clouston remarked that: 
In nine cases out of ten, melancholic patients assign as a cause of their misery what is not its cause at all. Here it is where their insane delusions, their false ungrounded beliefs, come in. I have analysed the "causes" assigned by melancholics that I have had under my care during the past seven years for their own depression, and I find them to be wrong in ninety per cent of the cases. ${ }^{82}$

This is illustrated by the frequent use of 'religious delusions' as a descriptive term. A large number of patients expressed sin and the wrath of God as the source of their mental suffering. For melancholic patients, these experiences were very real, but for physicians such spiritual explanations were a clear example of patients assigning an incorrect cause to their suffering.

In a case presented by Maudsley in The Pathology of Mind as the first of several 'ordinary illustrations of melancholia', a thirty-six-year-old man described as 'religious and of exemplary character' became, according to Maudsley, weighed down by a 'great depression' that soon produced 'blasphemous ideas' in his mind. Despite his best efforts to rid himself of these thoughts they continued to torture him; 'he was much distressed by this state of things, his gloom increased more and more, and at last he concluded that "he had done it," - namely, committed the unpardonable sin'. ${ }^{83}$ A belief in having committed 'the unpardonable sin' was repeatedly cited by Victorian physicians as a cause of their patients' suffering, and frequently constituted the focal point of the latter's 'delusions'. The specific nature of this sin was, however, rarely addressed directly; its meaning was firmly rooted in the Christian culture shared by patients and doctors, and appeared to require little explanation. However, while the concept was awarded scant attention in medical literature beyond its repeated appearance as psychological illusion that was a symptom of disease, it was widely discussed by theological writers of the period, both within the Church of England and among the evangelical denominations in Britain and North America. ${ }^{84}$

While 'the unpardonable sin' was a familiar concept in mid-nineteenthcentury writings on Christian morality, there appeared to be no clear agreement on exactly what kind of act constituted such a sin, which was often referred to in imprecise terms as a 'sin against the Holy Ghost'. In the first volume of Sermons, an 1864 monograph on Christian doctrine, the famous American clergyman and public speaker Henry Ward Beecher sought to settle this matter by providing a clear explanation of what was 
meant by this notion, suggesting that 'we are to regard the unpardonable sin, not as any one single offence, but as the state of heart which gives rise to conduct that is not pardonable. It is not an action; it is a condition of disposition or heart from which certain kinds of actions are developed'. Beecher's definition illustrates how Victorian melancholics expressed their religious distress, according to how this was interpreted and noted by their physicians. 'The unpardonable sin' appeared to convey a profound sense of guilt, sometimes for an abominable act that the patient claimed to have committed and sometimes for thinking of committing such an act. The overlap between lay and medical conceptions is evident also in Beecher's work-he suggested that an erroneous belief in having committed the unpardonable sin 'sometimes leads to insanity, and often is the leading feature of religious mania'. ${ }^{85}$

George Savage remarked upon the frequency of religious delusions, noting in melancholics 'a strong tendency to explain their misery by means of some text or religious dogma'. ${ }^{86}$ However, there existed a particular category of melancholic lunatics, Savage suggested, usually people who had been subject to a severe religious upbringing, particularly in 'narrow religious sects', whom he liked to refer to as 'the unpardonable sinners' in reference to the common delusion discussed above. His idea of what this most abominable of all sins was meant to refer to was notably different from the kinds of explanations offered by Christian thinkers. A man of science, Savage had no qualms about discussing particular sinful acts, and offered a more specific definition of 'the unpardonable sin' than that of 'the state of heart which gives rise to conduct that is not pardonable' given by Beecher. 'In many cases', Savage suggested to his readers, 'it refers to some sexual abuse'. Thus, the idea often arose following a period of excessive masturbation. ${ }^{87}$

While 'the unpardonable sin' was frequently noted by contemporaneous writers as a recurring delusion in melancholia, Savage appeared to be alone in his reference to immoral sexual conduct. Maudsley did, however, elaborate on the historical origins of this delusion, suggesting that the 'conviction of having committed the unpardonable sin' had existed as 'a common delusion of melancholics since the disciples of Christ introduced that doctrine to mankind'. Thus, the same delusion would not have been possible for 'an ancient Greek who was suffering from the same form of disease'; rather, he would have believed himself 'to be pursued by the Furies'. ${ }^{88}$ George Blandford, who spent most of his career 
in private practices in London, found the presence of this particular delusion to be a useful diagnostic guiding tool, since it suggested 'that the patient's condition is one of melancholia'. ${ }^{89}$ Blandford did not, however, hold the delusional belief in having committed the unpardonable sin to be a particular cause of suicidal intent in melancholic patients. Rather, he suggested that the suicidal tendency was often strongest in patients suffering from simple, or non-delusional melancholia, but that, on the whole, all melancholic patients were 'to be looked upon as suicidal'. 90 As we shall see below, while delusions of guilt were often seen in late Victorian medico-psychological literature as a driving force in the suicidal intent of many melancholics, the symptom was equally perceived as being particularly prominent in individuals suffering from 'simple' melancholia, where no delusions were present, and in such cases it was the very absence of delusions that was given as the chief cause of the suicidal tendency.

\section{Nosological Shifts: Maudsley Revisited}

Henry Maudsley's published work on mental disease serves as a useful reference point for the changing character of melancholia in the second half of the nineteenth century, as it exemplifies many of the wider debates and tensions that existed in relation to the status and definition of this diagnosis. When the first edition of Maudsley's textbook on mental physiology and pathology was published in the late 1860s, melancholia was variably seen as an independent disease category, or as a form of monomania, moral or partial insanity, or as variation of mania proper. As shown in Chapter 4, in 1867 Maudsley had classified non-delusional melancholia together with non-delusional mania under 'affective insanity', while melancholia proper was assigned to the broader category 'ideational insanity', together with mania, general paralysis, dementia, and idiocy. ${ }^{91}$ In 1879, a third revised edition of the second half of The Physiology and Pathology of the Mind was published as a separate volume entitled The Pathology of Mind. ${ }^{92}$ Like many of his peers, Maudsley noted the difficulties arising when attempting to categorise mental disease correctly and maintained that, for the time being, a system whereby illnesses were divided according to symptoms rather than their 'real nature' was, while provisional, necessary for practical reasons, in order to make the process of diagnosing patients less complex and laborious. ${ }^{93}$ When observing patients in the asylum, Maudsley argued, the most striking contrast in terms of symptoms was that between mania and melancholia, which 
could be further divided into 'general' and 'partial', the latter suggesting that 'the intellectual disorder is limited to a few ideas'. ${ }^{94} \mathrm{He}$ suggested that this separation of insanity, with the third addition of general paralysis, corresponded to the traditional symptomatologic division that could be found in the work of Esquirol. These three types were, Maudsley remarked, discernible even to the untrained eye of a layman. However, upon closer examination of an asylum population the medical expert would soon discover a more complex and rich picture. Most importantly, one would not be able to escape the fact that in many lunatics the mental disease was one in which any intellectual derangement, even of the partial kind, was wholly absent. The skilled observer would find that such forms of madness where emotion was only or primarily affected were by far the most common; indeed, Maudsley went so far as to suggest that 'the affective disorder has been the fundamental trouble in almost all cases that have not been produced at once by direct physical injury' ${ }^{95}$ Thus, he reaffirmed his previous assertion from 1867, when he had cautioned his peers against the dangers of failing to recognise disorders of affect as proper forms of madness. ${ }^{96}$

Maudsley had made some changes to his nosology from previous editions, but maintained the separation between 'affective' and 'ideational' insanity, to which a third umbrella category, 'amentia', was added. Both melancholia and mania were placed in the second category of ideational insanity together with monomania and dementia, whereas affective insanity contained only two subclasses, 'instinctive' and 'moral'. Impulses to commit suicide were, Maudsley argued, particularly common in forms of madness where only the affective life was disordered, and was presented as closely related to homicidal and other destructive impulses.

The classification system presented in the 1879 edition of The Pathology of Mind had a strong air of a work in progress about it. Maudsley suggested as much himself, stating that 'I might abolish the division of affective insanity altogether, and place the varieties belonging to it under mania and melancholia, dividing these respectively into mania with delusion, and mania without delusion, and into melancholia with or without delusion'. ${ }^{97}$ However, while he remained formally equivocal on whether or not melancholia should be classified as a single disease entity, he nevertheless proceeded to award an entire chapter to this form of insanity, a significant change from previous editions of the textbook. In a fourth edition of The Pathology of Mind published in 1895 Maudsley's nosology was revised in much the same way as anticipated, with the result that 
melancholia-particularly in its simple, non-delusional form-received more attention than any other form of madness. ${ }^{98}$

A comparatively strong focus on non-delusional melancholia was already apparent in the 1879 edition, where Maudsley suggested that it commonly appeared as the first stage of the disease, and sometimes persisted for the duration of illness. While the absence of delusion meant that the patient was able to conduct rational thought processes, their mental state would become 'profoundly changed notwithstanding: his feelings regarding persons and events are strangely perverted, so that impressions which would naturally be agreeable are painful'. ${ }^{99}$ One of the most difficult aspects of melancholia for those who suffered from it, Maudsley argued, was the fact that the morbid feelings and ideas appeared so wholly unnatural and without reason, and often seemed to the patient's mind to have appeared quite suddenly, as if from out of thin air. For this reason, he argued, the melancholic patient would often draw the conclusion that the mental suffering had supernatural causes, as a form of divine retribution. However, the patient's belief that the emotional suffering was in response to having committed 'the unpardonable sin' had, Maudsley argued, a medical explanation. Morbid ideas and emotions might appear to arise 'spontaneously' as if they were conjured up by 'the suggestion of an evil spirit', but in actual fact they were the result of a traceable physiological process:

There is, first, a possible organic suggestion coming from a particular organ of the body in consequence of the special sympathies which the brain has with the different organs; secondly, there is that constant unconscious mental operation - more active perhaps when the brain is in an abnormal state - whereby the revival of latent ideas and feelings frequently takes place without our being able to give any account of it; thirdly, impressions from without, which seem so trivial as to be hardly noticed at the time, may still have their effects upon the mind, and, when the brain functions are disordered and overclouded by gloomy feeling, may be worked up into strange morbid ideas; and lastly, an idea may be excited sympathetically by another idea to which it has no apparent relation, particularly in a morbid brain, just as the muscles may notably be sympathetically excited sometimes by the contraction of certain other muscles with which they have no normal functional connection. ${ }^{100}$ 
Maudsley agreed with Clouston's remark that melancholic patients, while often able to think rationally, were not aware of the correct source of their altered mental state, and this was in itself one of the most difficult aspects of this disease, Maudsley suggested. Because melancholics were often able to think quite clearly and engage in rational conversation, their simultaneous inability to explicate their own apparently irrational suffering constituted a tremendous source of despair. ${ }^{101}$ This was also one of the main reasons why they were often driven to suicide. The key to understanding suicide lay, Maudsley argued, in 'the instinctive love of life', which he held up as the 'real effective force against suicide'. This instinct was built into the constitution of each individual in the same way as the automated actions 'of the heart and of respiration'. Following from this, suicidal tendencies were evidence that 'the organic element' of the melancholic sufferer was 'so wanting in this fundamental quality that it could not assimilate and increase, but must be assimilated and decrease'. ${ }^{102}$ In this way, the apparent contradiction of suicidality in melancholic patients suffering from religious delusions could be explained. It might seem 'curiously inconsistent', Maudsley remarked, that a person who perceives their mental suffering to be the result of having sinned against God and who fears 'eternal damnation' should be driven towards the very outcome they fear the most and which they believe is the cause of their suffering. This showed, he argued, that 'nature' was 'deeper and stronger than creed', driving the melancholic towards suicide 'by an impulse whose roots go far down below any conscious motive'. ${ }^{103}$ This observation would later lead Maudsley to suggest that people suffering from simple or non-delusional melancholia were the most likely to commit suicide, and that such individuals were able to arrive at the decision through rational deliberation, as the only evident solution to intolerable mental pain and depression.

\section{TOWARDS a STANDARDised Diagnosis}

In the last quarter of the century melancholia was solidified and homogenised chiefly in two ways. On the one hand, biomedical explanatory frameworks for mental disease were the norm for British physicians in the second half of the century, and in this context variations on physiological reconstitutions of melancholia as 'disordered emotion' were widely adopted. On the other hand, the range of symptoms listed was more focussed with less variation in the terminology used by different physicians. While earlier conceptions of melancholia were arguably more 
coherent and unified than descriptions of other forms of madness, the symptoms described by medical writers and the language used in such descriptions exhibited a far greater degree of idiosyncrasy than those of the late Victorian period. This shift was particularly pronounced in the nosological sections of textbooks on mental disease, and in published journal articles. But much is also revealed in the language used in patient journals and other asylum records, as well as in the case studies physicians liked to attach as illustrations to their nosological writings. However, as will be seen below and in the next chapter, the unifying symptom terms that were increasingly deployed in late nineteenth-century Victorian literature functioned in different ways. Mental pain and depression were both symptoms emphasised as defining features of melancholia in nosological writings, but the former rarely featured in case studies involving direct descriptions of individual patients' mental states. Its chief usefulness can be seen as streamlining diagnostic criteria for the purpose of textbook descriptions of melancholia; in other words, mental pain served as an umbrella term, a sort of professional shorthand, for a multitude of different expressions of distress and suffering.

In the last two decades of the century, case studies of melancholia made regular appearances in medical journals (particularly the Journal of Mental Science). Suicidal tendencies were frequently highlighted as a key symptom, such as in an article by one of Thomas Clouston's assistant physicians at Morningside in Edinburgh. Recounting a case of 'profound' and 'suicidal' melancholia, Carlyle Johnstone described the patient, a forty-year-old woman, who was admitted after a period of insanity lasting 'several weeks'. The patient's history, as derived from her medical certificate, suggested that she had been 'threatening to commit suicide' and 'had taken very little food'. Overall, '[h]er mental condition was one of profound depression', she was described as anxious and agitated and 'exclaiming that she was lost'. After several months in the asylum, she was still considered to exhibit suicidal tendencies, she reportedly stated on several occasions that 'she wants to be killed', and 'attempted to commit suicide' a number of times while on the ward. ${ }^{104}$

In a case of 'melancholia followed by monomania of exaltation', a twenty-nine-year-old woman was equally described as 'suicidal', with the propensity chiefly brought on by religious delusions: 'She felt that she was doomed to everlasting punishment'. ${ }^{105}$ A forty-year-old woman was admitted to the pauper asylum in Worcester in a state of 'acute melancholia'. Several 'superficial scratches' to the skin were found on her body, 
believed to have been 'self-inflicted with suicidal intent'. She claimed to have inserted a needle into her stomach 'with the object of taking her life', but none was discovered upon examination. The author noted that she continued to be 'very suicidally inclined' until she eventually died, presumed to be suffering from phthisis. During the autopsy, a needle was discovered buried in her abdomen. ${ }^{106}$ Twin sisters were admitted to the Warwick County Asylum in 1900, and were both diagnosed with melancholia upon admission. Arthur Wilcox, head physician at the hospital, described them both as having 'the same dominant delusion, viz., that she herself was the most wicked woman alive and was unfit to live, and both attempted suicide just before admission'. ${ }^{107}$

George Savage described a similar case of a young woman who was admitted to Bethlem after a brief melancholic episode reportedly triggered by the birth of her child. As her mental state deteriorated, 'she became suicidal and violent, refused food, said she was inhumanely wicked, that she has ruined her husband, and ought to be got rid of ${ }^{108}$ Savage wrote extensively on melancholia in his major textbook, Insanity and Allied Neuroses, which was published in several editions from the mid-1880s onward, and paid particular attention to suicidal tendencies in melancholic patients. In addition to a handful of monographs, he was a regular contributor to the Journal of Mental Science (which he also co-edited with Daniel Hack Tuke between 1878 and 1892) as well as general medical journals. ${ }^{109}$ In the first (1884) edition of his textbook, Savage regretfully noted that the physiological basis of mental disease was at present poorly understood. At the same time, he was optimistic that it was only a matter of time until the microscopic functions of the brain would be revealed to medical scientists. ${ }^{110}$ Like Maudsley, he argued that at present the different forms of mental disease must be organised and described according to their external manifestations. He did, however, envisage a time when mental disorders could be classified 'according to the physiological changes which take place in the nerve centres'. While certain forms of insanity resulted in observable structural changes to brain tissue, other forms 'depend for their origin on the existence of some bodily defect or degeneration, which, causing irritation at the periphery, in the end sets up brain disease by a continuity of the nervous tissues, or by some other reflective process'. 111 
Thus, while Savage expressed greater reservations about what physiological research could presently reveal about the internal nervous operations of people believed to suffer from mental disease, he nevertheless recognised the prevailing model for explicating disordered mental functions. While advising his readers that 'the pathological basis of melancholia' remained, as yet, uncertain, it appeared that the disease could be attributed to impaired nutrition of the nervous centres and the conducting system'. ${ }^{112}$ Savage offered the following descriptive summary of melancholia:

Melancholia is a state of mental depression, in which the misery is unreasonable either in relation to its apparent cause, or in the peculiar form it assumes, the mental pain depending on physical and bodily changes, and not directly on the environment. ${ }^{113}$

On the pathology and aetiology of the disease, Savage explained that the 'mental pain' in melancholia could be the result of 'change in the nutrition of the brain depending on some general or local disease', but equally this 'disordered process' could occur through the 'nervous system' becoming exhausted. ${ }^{114}$ In addition to these possible origins, Savage warned that 'any cause, bodily or mental, which worries the body or mind, any cause which by its constancy, or by its frequent repetition, gives no chance of repair, may also cause melancholia' 115 Thus, Savage equally allowed for the idea, put forward by Griesinger, Laycock, and others, that morbid cerebral action could be triggered by negative thoughts alone.

As the works discussed above illustrate, towards the end of the century the melancholia diagnosis was increasingly coherent and standardised, coalescing around four key symptoms: depression, suicidal tendencies, mental pain, and religious delusions. The focus on suicidality also facilitated another development that would have profound and lasting consequences for the ways in which psychiatric knowledge is brought to bear upon emotional states. The suicidal impulse was often seen as strongest in people suffering from simple, or non-delusional, melancholia, as they were able to reason about their suffering. This meant that physicians were increasingly concerned with this milder form of the disorder, which sat uneasily on the border between sanity and insanity. In this way, a final key development in the reconceptualisation of melancholia as a modern biomedical disorder, and a precursor to twentieth-century depression, occurred: the expansion of the realm of psychiatric knowledge to include emotional states not considered strictly pathological. 


\section{Obscuring the Boundary between Normal and Pathological Emotions}

As noted in Chapter 4, Griesinger had argued for early intervention to prevent melancholics from deteriorating into more severe forms of insanity. This argument was echoed by British physicians in the last quarter of the century. George Savage emphasised that early diagnosis and treatment of melancholia was imperative. In its simple form, which often constituted the early stages of illness, melancholia might not manifest as a full-blown mental disorder; in some cases it was only distinguishable by 'slight perversions of feeling and intellect of a gloomy nature'. However, echoing Griesinger, Savage argued that it was of 'the utmost importance' that even this mild form or stage of the disease was recognised as pathological and that patients gain access to diagnostics and treatment. If simple melancholia was not properly acknowledged, the disorder 'may become chronic and incurable'. 116 Treatment and confinement was also important for another reason-to prevent melancholics from committing suicide. Despite his sceptical stance towards statistics on suicidal patients noted above, Savage held that one of the most significant features of melancholia was the frequency with which its sufferers exhibited suicidal tendencies. He suggested that the suicidal propensity could arise from a number of causes, some of which were associated with delusions, particularly of a religious kind. However, while patients suffering from other forms of insanity were sometimes known to attempt or commit suicide, such instances were often accidental, whereas 'suicide must ever be looked upon as one of the dangerous symptoms connected chiefly with melancholia'. ${ }^{117}$

William Bevan Lewis also noted the problem of suicidal intent in nondelusional melancholics, who were able to reason about their suffering and search in vain for a rational cause. As medical director at the Wakefield Asylum in West Riding, Yorkshire, and successor to the famous neurologist James Crichton-Browne, Lewis readily embraced a biomedical model for melancholia. This can at least in part be attributed to the context in which he worked; at West Riding there was a significant focus on cerebral post-mortem examinations and diagnostics were constituted within a solid biological framework. ${ }^{118}$ His commitment to neurology and neurophysiology was in strong evidence in his textbook, which commenced with a substantial section on anatomy and histology, made up of several detailed chapters on the various parts of the brain and spinal cord. He went on 
to describe simple melancholia as 'forms of a purely emotional or affective insanity, where there is mental pain or emotional distress apart from obvious intellectual disturbance' ${ }^{119}$ It was not, however, the intensity of the mental pain that set it apart from similar feelings in healthy individuals, but rather its cause. If 'the mental pain is the result of trivial exciting agencies, if moral or physical agencies arouse emotional states out of all proportion to what would occur in a healthy mind, then we infer that the grey cortex of the brain is so far disordered as to functionate abnormally, and we speak of the result as pathological depression'. ${ }^{120}$

Lewis quoted Griesinger on the topic of mental pain as a " disproportionately excessive" reaction' in melancholia, suggesting that ' $[\mathrm{e}]$ motional disturbances as the result of disease differ from the normal reactions of health, not only in volume, but also in nature'. Drawing upon Herbert Spencer's psychology, Lewis went on to suggest that part of the problem lay in 'pain' being a 'non-relational' emotion. This meant that it could not easily coexist with other emotional states, making it difficult to estimate 'the degree of mental alienation in melancholia'. ${ }^{121}$ This perceived inability to deduce the extent of the melancholic patient's psychological pain and deterioration made the threat of suicide all the more insidious. He suggested, however, that because patients were often capable of rational thought, they struggled to resist their suicidal propensities. ${ }^{122}$

This tension between rational thought and emotional pain in suicidal melancholics was discussed in detail by Charles Mercier in his Sanity and Insanity (1890). A consulting physician on mental disease at Charing Cross Hospital in London, Mercier encountered melancholic patients outside the asylum walls, and paid particular attention to suicidality in melancholic sufferers in the earlier, non-delusional stages of the disease. He alerted his readers to the 'tendency to suicide' that was a common feature of melancholia, and went on to emphasise the unnaturalness of self-inflicted death. 'Suicide', he argued, 'is so complete and violent a reversal of the strongest and most fundamental of instincts - the instinct of self-preservation - that its origin, and the frequency of its occurrence, are extremely puzzling'. ${ }^{123}$ However, when describing this phenomenon in melancholic patients, Mercier offered an explanation for the apparent enigma of suicide. With a nod to the growing body of non-medical research on the causes and prevalence of suicide in Europe, he observed that suicides were clearly committed by sane individuals in many cases, and could result from of a host of factors, such as financial troubles or unrequited love. In light of this knowledge, Mercier suggested that 
the way out of a misery which is autogenetic, and does not correspond with or depend on adversity of circumstances, may be the same as that out of a misery, the same degree, which is justified by the circumstances in which the organism is placed. There may be no justification in his circumstances for the misery which the melancholy man experiences, but his misery is as acute, as real, as profound as that of the man whose circumstances are extremely adverse; nay, there is no such misery as that of melancholia; and under the pressure of this feeling suicide may be the natural and quasinormal course to take. Here, then, a large class of suicidal cases receives an explanation on grounds which import no new principle of action into human motives, and which harmonize with the general course of human nature. ${ }^{124}$

While suicidal intent may in a healthy individual arise from organismenvironment interaction where an adverse event might trigger a desire to commit suicide, in melancholic patients a similar kind of event would occur internally, with the diseased mental state itself, rather than some external cause, producing the adverse reaction. In this way, from the argument that suicide was the antithesis of the fundamental evolutionary principle - the organism's struggle for self-preservation-Mercier arrived at the conclusion that when held against the pain and misery of melancholia, suicide would in fact appear as a natural act and a reasonable solution to intolerable suffering.

Maudsley arrived at much the same view a couple of years later. In an article entitled 'Suicide in Simple Melancholy', which appeared in the Medical Magazine in 1892, he presented a narrative of melancholic suffering that was much revised from his earlier published work on the disease. Maudsley's choice of word is important to note-the use of 'melancholy' rather than the medical 'melancholia' speaks to an emphasis on the very early stages of the disease, when the sufferer's state of mind was not yet disordered to such an extent that one might speak of insanity proper. Yet, like Savage, Maudsley firmly maintained that this condition warranted medical attention, primarily due to the often overwhelming desire to commit suicide in such individuals. Indeed, he suggested that the suicidal propensity was as a rule much more intense, persistent, and ultimately more dangerous than in people suffering from melancholia proper. In the latter, suicidal thoughts might plague the patient for years before any action would be taken, whereas the simple melancholic was far more likely to end their life swiftly. ${ }^{125}$ 
Why was this so? It was not the case, Maudsley argued, that the pain was more intense in simple melancholy than in melancholia proper. Rather, the problem lay in the fact that, in the absence of any intellectual derangement, the individual was able to reason about their condition and thus fully appreciate the absurdity and hopelessness of such misery without apparent cause. It was this absence of any traceable external circumstances to explain the mental pain that marked this state of mind as disordered, despite the patient being otherwise 'sane'. If such misery was caused by 'misfortune, bereavement, soured hope, disdained love, crosses or losses in business, or other sufficient blow to self-love or self-interest', then the reaction was to be considered normal, and the individual would soon recover. However, if the suffering arose 'due to internal failure of the springs of re-action, without external cause or in measure and duration out of all proportion to such cause as there may have been, then it is morbid'. 126

The mental pain of simple melancholics was consequently of a particularly excruciating kind. They would find themselves able to take in their surroundings and engage with the world, yet feeling utterly trapped in a permanent state of emotional suffering:

Sane enough to feel keenly what they suffer and to contrast their woeful deadness with the joyous energy around them, crushed to despair by the serene continuity of things in contrast with the discontinuity of their interest in them, in the world but not of it, sufferers not doers - they cannot bear the burden of a wretched existence. ${ }^{127}$

For such persons, then, '[o]ne way of escape alone suggests itself, dim and undefined in his mind and shrunk from with horror at first, but viewed more nearly and clearly when he feels his anguish too great to be borne longer: it is suicide'. ${ }^{28}$ Thus, in simple melancholy the unnatural act of suicide appeared as the only natural solution to intolerable suffering. Following from this, Maudsley argued that upon examination every suicide could be found to have an 'explanatory' cause. In cases of non-delusional melancholy, the expounding factor was unequivocally clear:

Suicide of this sort, springing from suffering that is intolerable, is natural in motive and logical in fact, whatever may be thought of it from a moral standpoint: the outcome in consciousness of the sum of the despair of 
the life-lacking organic elements, it is a supreme, final and (if we may use the word in this connection) fit act of adjustment to the outer world with which the individual can no longer contend. It is the remedy for the malady of life which has become insupportable. ${ }^{129}$

Such an unambiguous rationalisation of suicide is noteworthy even for a medical scientist of Maudsley's convictions. ${ }^{130}$ Within a philosophy of mind firmly rooted in an evolutionary paradigm, suicide resulting from the internal conflict of melancholic suffering could nevertheless be construed as natural and logical. Indeed, it was precisely the conflict between each organism's desire for self-preservation and the profound mental pain of simple melancholy that allowed the suicidal propensity to arise with such force and intensity. '[W]here the love of life is struggling against its ebb', Maudsley warned, 'the misery is the greatest and the danger most urgent' ${ }^{131}$

While the Medical Magazine article referred to the condition as 'simple melancholy' and emphasised its ambiguous status in relation to insanity proper, a few years later Maudsley reworked the article to fit into a chapter on melancholia in the final, much revised, edition of The Pathology of Mind (1895). This version of the textbook contained two, significantly expanded, chapters devoted to melancholia, including a comprehensive section on 'simple melancholia'. This largely mirrored the article on 'Suicide in Simple Melancholy', with a notable modification being the use of 'melancholia' in place of 'melancholy'. Maudsley described this milder form of melancholia proper as 'a class of cases of mental depression' where 'there is neither delusion nor actual disorder of thought'. He maintained that such conditions were not melancholia in strict sense, since there is no real derangement of mind', rather in these states there was 'only a profound pain of mind paralysing its functions - an essential psychalgia'. ${ }^{132}$

While in the 1860s Maudsley had issued a sharp caution against the failure to properly recognise non-delusional, affective disorders of mind as forms of true madness, three decades later he arrived at a conclusion that appears, at first glance, to contradict his former argument. However, what we are witnessing here is the infancy of a process whereby medicopsychological (and later psychiatric) attention was increasingly brought to bear upon aspects of the human emotional and cognitive life that were not considered to be states of insanity in the proper sense. ${ }^{133}$ It is not possible within the scope of this book to address this important shift 
in how post-nineteenth-century medical psychologists and psychiatrists would constitute the relationship between human emotion, behaviour, and pathology. However, the implications of Maudsley's revision of his earlier argument must not be overlooked. The decision to award significant attention in a textbook on mental pathology to the description and analysis of an emotional state which by his own account was not a form of disease, was, while perhaps more subtly done, nonetheless at least as critical a revolution in medical thinking as the early nineteenth-century argument that some forms of madness were chiefly of the affective kind.

\section{CONCLUSION}

This chapter has mapped the key ways in which melancholia as was modernised and standardised in the final decades of the nineteenth century. Through this process, the diagnosis came to centre upon four key symptoms: depression, suicidal tendencies, mental pain, and religious delusions. It is important to note, however, that the developments described here were neither universal nor did they occur in a simple, linear fashion. Biomedical ways of explaining the mind continued to rely in some instances on terminology and concepts that pre-dated nineteenthcentury experimental physiology. Much like psychiatry today, Victorian medical psychologists struggled to make sense of the mind in strictly scientific terms, and despite their strong epistemological commitment to biomedicine, they were forced to make use of other tools in order to carry out many of the practical aspects of their work. In particular, physiological explanations of mental operations were of little use when it came to diagnosing patients arriving at the asylum or hospital. Here, observable and communicated 'symptoms' provided the major source of information about which type of disease physicians were faced with. However, the symptoms described in this chapter were not, as a rule, communicated as such by the patients. The intellectual work required to turn the chaos of human emotions that met physicians on the asylum wards into recordable, classifiable symptoms was thus considerable. The uneasy relationship between what was observed, communicated, recorded, and published is the focus of the next chapter, which traces melancholia as a diagnosis on its journey between the casebook and the textbook. 


\section{Notes}

1. John Charles Bucknill, "The Diagnosis of Insanity," Journal of Mental Science 2 (1856): 229.

2. Roger Smith, Being Human: Historical Knowledge and the Creation of Human Nature (Manchester: Manchester University Press, 2007), 122.

3. George H. Savage, Insanity and Allied Neuroses: Practical and Clinical (London: Cassell, 1884), 12.

4. Savage, Insanity, 12. Such concerns have persisted in psychiatry, most recently voiced in response to the fifth edition of the DSM. See the Conclusion of this book.

5. Thomas S. Clouston, Clinical Lectures on Mental Diseases (London: J. \& A. Churchill, 1883), 112.

6. An Act (8 O 9 Vict. c. 100) for the Regulation of the Care and Treatment of Lunatics, 1845, Schedule D, Section 46: “Order for the Reception of a Pauper Patient".

7. Thomas N. Brushfield, "On Medical Certificates of Insanity," The Lancet 115 (1880): 712 .

8. Edwin S. Schneidman, Suicide as Psychache: A Clinical Approach to SelfDestructive Behavior (Plymouth: Rowman and Littlefield, 1993), 51.

9. E.g. Clouston, Clinical Lectures; Richard von Krafft-Ebing, Die Melancholie: Eine klinische Studie (Erlangen: Ferdinand Enke, 1874); Henry Maudsley, The Pathology of Mind: A Study of Its Distempers, Deformities, and Disorders, 4th ed. (London: Macmillan, 1895).

10. See e.g. Steven Mee, et al., "Psychological Pain: A Review of Evidence," Journal of Psychiatric Research 40, No. 8 (2006): 680-690; Israel Orbach, et al., "Mental Pain and Its Relationship to Suicidality and Life Meaning," Suicide and Life-Threatening Behaviour 30, No. 3 (2003): 231-241.

11. See the Introduction and Chapter 3 for discussions on differing meanings of this term in the Victorian period and the present.

12. Diagnostic and Statistical Manual for Mental Disorders, Fifth Edition (DSM -5) (Washington, DC: The American Psychiatric Association, 2013), 161; International Statistical Classification of Diseases and Related Health Problems, 10th Revision (ICD-10), World Health Organisation, 2010, section F32 ("Depressive Episode"), http://apps. who.int/classifications/icdl0/browse/2010/en\#/F32 (last accessed $08 / 05 / 2013)$.

13. See e.g. Savage, Insanity, 151; Griesinger, Die Pathologie und Therapie, 213; Clouston, Clinical Lectures, 32; William Bevan Lewis, A Text-Book of Mental Diseases, 2nd ed. (London: Charles Griffin, 1899), 115.

14. See e.g. Samuel Smiles' Victorian bestseller: Samuel Smiles, Self-Help, with Illustrations of Character and Conduct (John Murray: London, 1859). 
15. Maudsley, Physiology and Pathology of the Mind, 322.

16. Henry Monro, Remarks on Insanity: Its Nature and Treatment (London: John Churchill, 1851), 1.

17. A Bill to Regulate the Care and Treatment of Insane Persons, House of Commons, Session 1828 (78), Vol. I.323.

18. As decreed by a parliamentary Act of that year: Licensed Lunatic Asylums: A bill for amending the Laws Relating to Houses Licensed by the Metropolitan Commissioners and Justices of the Peace for the Reception of Insane Persons, House of Commons, Session 1842, Vol. III.113.

19. Report of the Metropolitan Commissioners in Lunacy to the Lord Chancellor, Presented to Both Houses of Parliament by Command of Her Majesty (London: Bradbury \& Evans, 1844), 178-179.

20. The Victorian fascination with numbers (mirrored in much of nineteenth-century Europe) was the focus of a conference organised by the British Association for Victorian Studies, held at Royal Holloway in London. A full list of speakers and papers can be found here: http:// bavs2013.wordpress.com/programme/ (last accessed 03/08/2013).

21. Elis Malmeström, Carl von Linné: Geniets kamp för klarhet (Stockholm: Bonniers, 1964), 66.

22. Michel Foucault, The Order of Things: An Archaeology of the Human Sciences (London: Routledge, 2002 [1966]), 144.

23. Geoffrey C. Bowker and Susan Leigh Star, Sorting Things Out: Classification and Its Consequences (London: The MIT Press, 1999), 17.

24. On the emergence of medical statistics, see Eileen Magnello and Ann Hardy, eds., The Road to Medical Statistics (Amsterdam and New York: Rodopi, 2002).

25. Terrence D. Murphy, "Medical Knowledge and Statistical Methods in Early Nineteenth-Century France," Medical History 25 (1981): 303304.

26. Murphy, Statistical Methods, 305.

27. Murphy, Statistical Methods, 307-308.

28. Elaine Murphy, "The Administration of Insanity in England 1800 to 1870," in The Confinement of the Insane: International Perspectives, 1800-1965, eds. Roy Porter and David Wright (Cambridge: Cambridge University Press, 2003), 337.

29. David Wright, "The Certification of Insanity in Nineteenth-Century England and Wales," History of Psychiatry 9 (1998): 272-274.

30. An Act ( 8 \& 9 Vict. c. 100) for the Regulation of the Care and Treatment of Lunatics, House of Commons, No. 373, Vol. IV.181, 1845; Lunacy Asylums and Pauper Lunatics. A Bill to Amend the Law Concerning Lunatic Asylums, and the Care of Pauper Lunatics in England, House of Commons, No. 358, Vol. IV.7, 1845.

31. Wright, "The Certification of Insanity," 274. 
32. A similar body, the 'Board of Commissioners,' was set up for Scotland the following decade. An Act (20 \& 21 Victoria c. 71) for the Regulation of the Care and Treatment of Lunatics, and for the Provision, Maintenance, and Regulation of Lunatic Asylums in Scotland, 25 August, 1857.

33. Lunacy Commission, Circular Letters, Letter no. 69, May 7, 1857, The National Archives, Kew, Ref: MH51/236.

34. Lunacy Commission, Circular Letters, Letter no. 127, February 5, 1870, The National Archives, Kew, Ref: MH51/237.

35. Care and Treatment of Lunatics Act, Schedule (D.), Section 48.

36. Under Scottish law, two certificates were required for both private and pauper patients.

37. These templates underwent minor modifications with subsequent amendments of the Lunacy Act in 1853 and 1862.

38. Care and Treatment of Lunatics Act, Section 51.

39. While Scottish asylum physicians operated under a separate lunacy law and reported to their own Board of Commissioners, the result was largely the same in terms of the kind of statistics produced.

40. Another body created by the 1845 Acts; a group of appointed judges and physicians whose task it was to carry out regular 'visitations' of the asylums in their jurisdiction. Their findings and recommendations were included in the annual report of each asylum.

41. Care and Treatment of Lunatics Act, Section 60. Italics removed.

42. Lunacy Commission, Circular Letters, Letter no. 7, 19 January 1846, The National Archives, Kew, Ref: MH51/236.

43. Eric J. Engstrom, Clinical Psychiatry in Imperial Germany: A History of Psychiatric Practice (Ithaca, NY: Cornell University Press, 2004), 35-44.

44. "Proceedings at the Annual Meeting of the Medico-Psychological Association, held at the Royal College of Physicians, on Thursday, July 13th, 1865," Journal of Mental Science 11 (1865): 402-407.

45. "Proceedings at the Annual Meeting of the Medico-Psychological Association, held at the Royal College of Physicians, on Wednesday, July 31st, 1867," Journal of Mental Science 13 (1867): 402-403.

46. The Commission moreover took measures to ensure that the new tables were implemented by sending out a reminder to all asylum superintendents in 1870. See Lunacy Commission, Circular Letters, Letter no. 126, 3 February 1870, The National Archives, Kew, Ref: MH 51/237.

47. Twentieth Annual Report of the Commissioners in Lunacy to the Lord Chancellor, House of Commons, June 4, 1866, 44-46.

48. "Proceedings" (1867), 410.

49. Henry Maudsley, The Pathology of Mind, 3rd ed. (London: Macmillan, 1879), 296.

50. Maudsley, The Pathology of Mind, 3rd ed., 327. 
51. Savage, Insanity, 12.

52. Lunacy Commission, Circular Letters, Letter no. 156, 20 February 1876, The National Archives, Kew, Ref: MH51/237.

53. This is based on a survey of statistics and casebooks from the following asylums: Parkside (Cheshire), Brookwood (Surrey), Hanwell (Sussex), Bethlem (London), Morningside (Edinburgh), and Ticehurst (Sussex).

54. For a more in-depth discussion of this process, see Åsa Jansson, "From Statistics' to Diagnostics: Medical Certificates, Melancholia, and 'Suicidal Propensities' in Victorian Psychiatry," Journal of Social History 46, No. 3 (2013): 716-731.

55. See also e.g. W.F. Farquharson, "On Melancholia: An Analysis of 730 Consecutive Cases," Journal of Mental Science 40, No. 169 (1894): 196-206.

56. Thomas N. Brushfield, "Report of the Medical Superintendent for the Year 1854," in Annual Report of the Committee of Visitors to the Cheshire County Lunatic Asylum (Chester: Evans and Gresty, 1855).

57. Olive Anderson's study sheds light on the vexing questions facing physicians who were expected to care for 'suicidal' lunatics. See Olive Anderson, Suicide in Victorian and Edwardian England (Oxford: Clarendon Press, 1987), 402-405.

58. Lunacy Commission, Circular Letters, Letter dated 21 March 1877, The National Archives, Kew, Ref: MH51/237.

59. George Savage, "Constant Watching of Suicidal Cases," Journal of Mental Science 30 (1884): 17-19.

60. Savage, 'Constant Watching', 17.

61. 'Proceedings' (1865), 415.

62. 'Proceedings' (1865), 417.

63. Bucknill had also voiced concerns about the format of medical certificates a few years earlier. John Charles Bucknill, "On Medical Certificates of Insanity," Journal of Mental Science 7 (1860): 79-88.

64. Thomas N. Brushfield, "Report of the Medical Superintendent for the Year 1870," in Annual Report of the Committee of Visitors to the Surrey County Lunatic Asylum at Brookwood (London: Batten \& Davies, 1871), 21-22.

65. Brushfield, 'On Medical Certificates', 712.

66. Brushfield, 'On Medical Certificates', 712.

67. Brushfield, 'On Medical Certificates', 712.

68. Bowker and Star, Sorting Things Out, 24.

69. This tension has been the focus of much scholarly attention. See for instance Frank Turner, "The Victorian Conflict between Science and Religion," Isis 69 (1978): 356-376; Geoffrey Cantor, Thomas Dixon, and Stephen Pumfrey, eds., Science and Religion: New Historical Perspectives (Cambridge: Cambridge University Press, 2010). 
70. See for instance: Esther Cohen, The Modulated Scream: Pain in Medieval Culture (Chicago: Chicago University Press, 2009); John R. Yamamoto-Wilson, Pain, Pleasure, and Perversity: Discourses of Suffering in Seventeenth Century England (Farnham: Ashgate, 2013); Jan Frans van Dijkhuizen and Karl A.E. Enenkel, eds., The Sense of Suffering: Constructions of Physical Pain in Early Modern Culture (Leiden: Brill, 2009).

71. See for instance the special issue of Interdisciplinary Studies in the Long Nineteenth Century on 'Perspectives on Pain' (No. 15, 2012). See also Andrew Hodgkiss, From Lesion to Metaphor: Chronic Pain in British, French and German Medical Writings, 1800-1914 (Amsterdam: Rodopi, 2000); Joanna Bourke, "Pain, Sympathy, and the Medical Encounter between the Mid Eighteenth and the Mid Twentieth Centuries," Historical Research 85, No. 229 (2012): 430-452.

72. Javier Moscoso, Pain: A Cultural History (Basingstoke: Palgrave Macmillan, 2012), 106.

73. Astell is primarily known as an early advocate of women's education. See Joan Kinnaird, "Mary Astell and the Conservative Contribution to English Feminism," Journal of British Studies 19, No. 1 (1979-80): 53-75.

74. Mary Astell, "Letter V: To Mr. Norris," in Letters Concerning the Love of God, between the Author of the Proposal to the Ladies, and Mr. John Norris, eds. John Norris (London: Manship and Wilkin, 1705), 53.

75. Richard Fiddes, Fifty Two Practical Discourses on Several Subjects, Six of Which Were Never Before Published (London: Wyat, Took, Barber, and Clements, 1720), 639.

76. Cf. Emma Sutton on William James' perception of evil: "When Misery and Physics Collide: William James on 'the Problem of Evil'," Medical History 55, No. 3 (2011): 389-392.

77. Eighteenth-century medical works played an important part in fusing spiritual and scientific language. See e.g. David Hartley on mental pain in Observations on Man, His Frame, His Duty, and His Expectations, 4th ed. (Warrington, Johnson and Eyres, 1810 [1751]), 263.

78. This is discussed in Chapter 2. See also Hodgkiss, From Lesion to Metaphor.

79. Griesinger, Die Pathologie und Therapie. Griesinger used the more literal term 'psychischen Schmerz' rather than 'Psychalgie'.

80. J.M. Schiff, Lehrbuch des Physiologie des Menschen: I. Muskel- und Nervenphysiologie (Lahr: Verlag von M. Schauenburg \& Co, 1858-59).

81. Griesinger, Die Pathologie und Therapie, 34.

82. Griesinger, Die Pathologie und Therapie, 38. See also Maudsley, Pathology of Mind, 3rd ed., 360-361.

83. Maudsley, The Pathology of Mind, 3rd ed., 362. 
84. See e.g. D. Denham, "The Forgiveness of All Sin, Except the Sin Against the Holy Ghost," The Gospel Magazine 1, No. 2 (1841): 50-53; H.O. "On The Unpardonable Sin," The Christian Guardian and Church of England Magazine (1833): 257-259; Ichabod Smith Spencer, A Pastor's Sketches, or, Conversations with Curious Inquirers Respecting the Way of Salvation (New York: M.W. Dodd, 1868), 323-329.

85. Henry Ward Beecher, Sermons: No 1: Strength According to the Days (London: J. Heaton \& Son, 1864), 89-90.

86. Beecher, Sermons, 160.

87. Beecher, Sermons, 194.

88. Maudsley, The Pathology of Mind, 3rd ed., 360.

89. George Fielding Blandford, Insanity and Its Treatment: Lectures on the Treatment, Medical and Legal, of Insane Patients, 3rd ed. (New York: William Wood, 1886), 112.

90. Blandford, Insanity and Its Treatment, 142-143.

91. Henry Maudsley, The Physiology and Pathology of the Mind (London: Macmillan, 1867), 323. See Chapter 4 for details of Maudsley's earlier nosology.

92. Maudsley, The Pathology of Mind, 3rd ed. An independent third edition of The Physiology of Mind had been published three years previously: The Physiology of Mind (London: Macmillan, 1876).

93. Maudsley, The Pathology of Mind, 3rd ed., 297.

94. Maudsley, The Pathology of Mind, 3rd ed., 326.

95. Maudsley, The Pathology of Mind, 3rd ed., 328.

96. See Chapter 4.

97. Maudsley, The Pathology of Mind, 3rd ed., 329. Savage made a similar remark about his system, Savage, Insanity, 15.

98. See below.

99. Maudsley, The Pathology of Mind, 3rd ed., 358.

100. Maudsley, The Pathology of Mind, 3rd ed., 359-360.

101. Maudsley, The Pathology of Mind, 3rd ed., 358-359.

102. Maudsley, The Pathology of Mind, 3rd ed., 388.

103. Maudsley, The Pathology of Mind, 3rd ed., 385.

104. Carlyle Johnstone, "Case of Profound and Somewhat Prolonged Suicidal Melancholia; Diarrhaea with Fever; Recovery," Journal of Mental Science 31, No. 134 (1885): 203.

105. (author unknown), "Melancholia followed by Monomania of Exaltation," Journal of Mental Science 26, No. 116 (1881): 564.

106. G.M.P. Braine-Hartnell, "Acute Melancholia: Attempted Suicide by Inserting a Needle into the Abdomen. Death Nearly Thirteen Months After," Journal of Mental Science 39 (1893): 397-399. 
107. Arthur W. Wilcox, "Insanity of Twins; Twins Suffering from Acute Melancholia," Journal of Mental Science 47, No. 197 (1901): 349. Of interest is also e.g. F.A. Elkins, "A Case of Melancholia: Sudden Illness and Death," The Lancet 141, No. 3633 (1893): 858; A.F. Mickle, "Insanity of Twins: Twins Suffering from Melancholia," Journal of Mental Science 30, No. 129 (1884): 67-74; J. Neil, "Three Cases of Recovery from Melancholia After Unusually Long Periods," Journal of Mental Science 41, No. 172 (1895): 86-89; A. Patton, "Two Cases of Melancholia," Journal of Mental Science 31, No. 136 (1886): 499-501. 108. Savage, Insanity, 1884.

109. Savage's status as something of a Victorian medical celebrity was epitomised by his inclusion in Vanity Fair's 'Men of the Day' series in 1912. 'Men of the Day', Vanity Fair 1317 (1912).

110. Savage, Insanity, 9-10.

111. Savage, Insanity, 12-13.

112. Savage, Insanity, 130.

113. Savage, Insanity, 151.

114. On this aetiological point-the exhaustion of the nervous systemdescriptions of melancholia did at times intersect with those of neurasthenia. See Chapter 4.

115. Savage, Insanity, 162-163.

116. Savage, Insanity, 167.

117. Savage, Insanity, 193-194.

118. Jennifer Wallis, "The Bones of the Insane," History of Psychiatry 24, No. 2 (2013): 196-211 and Investigating the Body in the Victorian Asylum: Doctors, Patients, and Practices (London: Palgrave Macmillan, 2017).

119. Lewis, Mental Diseases, 138.

120. Lewis, Mental Diseases, 115.

121. Lewis, Mental Diseases, 116.

122. Lewis, Mental Diseases, 140.

123. Charles A. Mercier, Sanity and Insanity (London: Walter Scott, 1890), 349.

124. Mercier, Sanity and Insanity, 350.

125. Henry Maudsley, "Suicide in Simple Melancholy," Medical Magazine 1 (1892): 48-57.

126. Maudsley, "Suicide in Simple Melancholy," 46.

127. Maudsley, "Suicide in Simple Melancholy," 48.

128. Maudsley, "Suicide in Simple Melancholy," 48.

129. Maudsley, "Suicide in Simple Melancholy," 49.

130. Cf. contemporaneous sociological views, esp. Durkheim's 'anomie' as a cause of suicide. Émile Durkheim, Suicide: A Study in Sociology (London: Routledge and Kegan Paul, 1952 [1897]).

131. Maudsley, "Suicide in Simple Melancholy," 51. 
132. Maudsley, The Pathology of Mind, 4th ed., 167-168.

133. Another example of this was the increasing medical attention brought to bear upon 'minor' acts of 'self-mutilation' such as 'hair-plucking and face-picking' in this period, behaviours that were seen to occur in people suffering from mental disease, but which 'were also seen to blend seamlessly with the "nervous, fidgety, restless habits" that were equally considered "common among people who are not insane". Sarah Chaney, "Self-Control, Selfishness, and Mutilation: How Medical Is Self-Injury Anyway?" Medical History 55, No. 3 (2011): 380.

Open Access This chapter is licensed under the terms of the Creative Commons Attribution 4.0 International License (http://creativecommons.org/licenses/ by $/ 4.0 /)$, which permits use, sharing, adaptation, distribution and reproduction in any medium or format, as long as you give appropriate credit to the original author(s) and the source, provide a link to the Creative Commons license and indicate if changes were made.

The images or other third party material in this chapter are included in the chapter's Creative Commons license, unless indicated otherwise in a credit line to the material. If material is not included in the chapter's Creative Commons license and your intended use is not permitted by statutory regulation or exceeds the permitted use, you will need to obtain permission directly from the copyright holder.

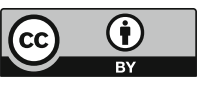

